Eduardo Figueredo MD

\title{
Changes in the intracuff pressure of the laryngeal masks airway caused by repeated use
}

Purpose: To observe the changes in permeability and elasticity in the cuff of the laryngeal mask airway (LMA) caused by repeated use. Methods: In vitro use was simulated on six \# 4 LMAs on 140 occasions. Ambient air was insufflated into the cuff until a value of $200 \mathrm{mmHg}$ intracuff pressure (ICP) was reached, and this was maintained for $50 \mathrm{~min}$. After each simulation, the LMA was sterilized at $121^{\circ} \mathrm{C}$ for $20 \mathrm{~min}$. After every 20 simulations insufflation of $40 \mathrm{ml}$ air was carried out to determine the maximum value of ICP (initial ICP), and after three hours, spontaneous deflation (final ICP) was measured.

The values of initial and final ICPs throughout the eight tests were attributed to the elastance and the permeability of the cuff respectively. At the end of the study the thickness of the wall of the cuffs was measured using an optical microscope.

Results: The initial ICP with the new LMA (first test) was of $191 \pm$ $4.4 \mathrm{mmHg}$. This value increased from the fifth test onwards until the end of the study. The value of the final ICP in the first test was $111 \pm 3 \mathrm{mmHg}$ and decreased with successive sterilizations. Between 80 and 100 simulations, initial ICP increased from 186.5 \pm 2.9 to $191,7 \pm 2.3(P=0.006)$. The thickness of the wall (694 $\pm 17 \mu$ ) was inversely related with the elasticity and the permeability of the cuff.

Conclusions: The "safe" life-span of the cuff of the LMAs, measured by the initial modifications of the physical properties of the silicone during simulations, was estimated to be 80-100 uses and was related to the thickness of its wall.

Objectif : Noter les changements de perméabilité et d'élasticité causés par l'usage répété du ballonnet de masque laryngé (ML).

Méthode: L'utilisation in volode six ML no 4 a été simulée 140 fois. De l'air ambiant a été insufflé dans le ballonnet jusqu'à obtenir une pression intraballonnet (PIB) de $200 \mathrm{mmH} g$ et maintenue ainsi pendant 50 min. Après chaque simulation, le $\mathrm{ML}$ a été stérilisé à $121^{\circ} \mathrm{C}$ pendant 20 min. Après 20 simulations, on a insufflé $40 \mathrm{ml}$ d'air afin de déterminer la valeur maximale de PIB (PIB initiale) et, après trois heures, on a mesuré le dégonflement spontané (PIB finale).
Les valeurs de PIB initiale et finale ont été attribuées, au fil des huit tests, à l'élasticité et à la perméabilité du ballonnet, respectivement. À la fin de l'étude, l'épaisseur de la paroi des ballonnets a été mesurée à l'aide d'un microscope optique.

R ésultats: La PIB initiale d'un M L neuf (premier test) a été de 191 $\pm 4,4 \mathrm{mmH}$. Cette valeur a augmenté à partir du cinquième test jusqu'à la fin de l'étude. La PIB finale du premier test a été de $111 \pm$ $3 \mathrm{mmH} g$ et a diminué avec les stérilisations successives. Entre les simulations 80 et 100, la PIB initiale a augmenté de 186,5 $\pm 2,9$ à $191,7 \pm 2,3(P=0,006)$. L'épaisseur de la paroi $(694 \pm 17 \mu)$ a été inversement reliée à l'élasticité et à la perméabilité du ballonnet.

Conclusion : La durée d'utilisation sans risque du ballonnet des M L, mesurée par les modifications des propriétés physiques initiales du silicone pendant les simulations, a été estimée à 80-100 usages et a été reliée à l'épaisseur de sa paroi.

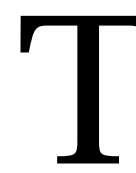

H E laryngeal mask airway (LMA) is manufactured from medical grade silicone rubber. Chemically, silicone rubber is different from other "organic" elastomers in its molecular make-up. Silicone, dimethyl polysiloxane, consists of silicone/ oxygen linkages, similar to those found in high temperature materials such as quartz and glass. When compared with many popular organic rubbers at room temperature, silicone is relatively weak but it has superior stability in its physical strength (tensile, tear, elongation and compression set) when subjected to temperature fluctuations. Liquid silicone rubber exhibits very little temperature dependence in its mechanical properties in a certain temperature range (from $-40^{\circ} \mathrm{C}$ to $+150^{\circ} \mathrm{C}$ ). This characteristic allows LM As to be sterilized (and reused) on a high, although undetermined, number of occasions.

When the device was first commercialised, the manufacturers recommended that it not be reused more than ten times. ${ }^{1,2}$ Later experience showed that the

From the D epartment of Anaesthesia, Torrecardenas H ospital, Almería, Spain.

A ddress correspondence to: Dr. Eduardo Figueredo, Paseo del Palmeral 4, Edf. Capri 6 - C, Aguadulce, 04720 Almería, Spain. Fax: 34950-21-21-08; E-mail: eduardofigueredo@hotmail.com

A ccepted for publication D ecember 17, 2000. 
LM As easily passed all the Device Performance Tests (Instruction $\mathrm{M}$ anual), as a result of which the manufacturers modified their recommendations, guaranteeing the safety of its use for up to 40 occasions. $^{3}$ $\mathrm{H}$ owever, some distributors of LM As have maintained that it may be used up to 200 times, providing it is sterilized in the appropriate manner. ${ }^{4}$

The present "in vitro" study was designed to estimate the wear caused by the sterilization procedures and repeated inflate/ deflate cycles produced during its use in modifying the elasticity and permeability of the cuff of the LMAs.

\section{$M$ aterial and methods}

Six unused size \#4 LMAs (The Laryngeal Mask Company Ltd., Nicosia, Cyprus) were selected in a randomised manner and arbitrarily designated as " $a$ ", " $b " .$. and " $f$ ". Each LMA was identified, for the course of the study, with a tape of different colour, which became indelible on sterilization. (Surg-I-Band, Codman / Johnson \& Johnson Professional, Inc., Raynham, M assachusetts, USA). Variations in cuff pressure that would have occurred during clinical use and the corresponding sterilization cycles were simulated in vitro.

For each measurement of the intra-cuff pressure (ICP), the pilot tube of each LM A was attached via a three-way tap to a pressure transducer (Supermon 7210, Kontron Instruments Ltd, Watford H erts, England) which was calibrated and zeroed. Each LM A was exposed to 140 simulations of use, in which, the cuff was insufflated with ambient air, up to the maximum values of ICP that are usually observed during anaesthetic procedures in which $\mathrm{N}_{2} \mathrm{O}$ is used (190$200 \mathrm{mmH} \mathrm{g}$ ), ${ }^{5,6}$ and the LM As remained inflated for approximately $50 \mathrm{~min}$, simulating the average duration of clinical use. After each simulation, the LMA was cleaned with water and sterilized by autoclaving at $121^{\circ} \mathrm{C}$ for $20 \mathrm{~min}$ (M atachana, serie 1000 Vapor Sterilizator, Barcelona, Spain) and the LM A was prepared for the next simulation with an interval of at least $24 \mathrm{hr}$. Before each new simulation the Device Performance T ests recommended by the manufacturers were carried out. ${ }^{7}$

After every 20 simulations tests the ICP was measured. The L M A cuff was deflated to a baseline pressure of $-25 \mathrm{mmH} \mathrm{g}$ and then inflated with a volume of $40 \mathrm{ml}$ of room air from a calibrated plastic syringe. The maximum value of ICP reached (initial ICP) was recorded, followed by the decrease in the ICP after a spontaneous deflation period of three hours (final ICP).

The complete study was made up of 140 simulations + sterilizations and eight tests. The first test was carried out on unused LMAs, before starting the simulations. Each test was repeated twice and the results averaged. Variations in the initial and final ICP values throughout the study were attributed to variations in the elasticity and permeability in the wall of the cuff respectively. All laboratory tests were carried out at room temperature $\left(21-24^{\circ} \mathrm{C}\right)$.

O nce the study was finished, samples $\left(1 \mathrm{~cm}^{2}\right)$ were taken from the side wall of each of the cuffs and its thickness was measured using an optic microscope with a micrometric eyepiece of $10 x$, a revolver of $1.25 \mathrm{x}$ and an objective of $2.5 \mathrm{x}$ (Leitz Ortholan ${ }^{\mathrm{TM}}$, G.M.B.M. Wetzlar, Germany). The thickness of the wall was related to the values of ICP of each LMA.

$D$ ata are presented as mean $\pm S D$. Averaged values of initial and final ICP obtained in each test were compared with the values in the following test by a impaired Student's t test. Significance was taken as $\mathrm{P}<0.05$.

Results

When the LMAs were unused (test \#1) insufflation of $40 \mathrm{ml}$ air produced an initial ICP of $191 \pm 4.4 \mathrm{mmH} \mathrm{g}$. This decreased slightly until test \#5 (80 simulations + sterilizations) and later increased throughout the study (Figure 1). The mean initial ICP after the eighth test was of $194.9 \pm 4.5 \mathrm{mmH}$ g. Between 80 and 100 simulations (test \#5 and \#6), the initial ICP increased from $186.5 \pm 2.9$ to $191.7 \pm 2.3 \mathrm{mmH} \mathrm{g}(P=0.006)$. After three hours spontaneous deflation the average final ICP value for the LM As in test \# 1 was $111 \pm 3 \mathrm{mmH} \mathrm{g}$ and this decreased with repeated use.

There were differences between the individual values of the LM As, both in the initial ICP values (range 184-196) and in the final ICP (range 107-115) when these were unused. The latter performance throughout successive tests showed a relative parallelism among the results of each LMA (Figures 2, 3).

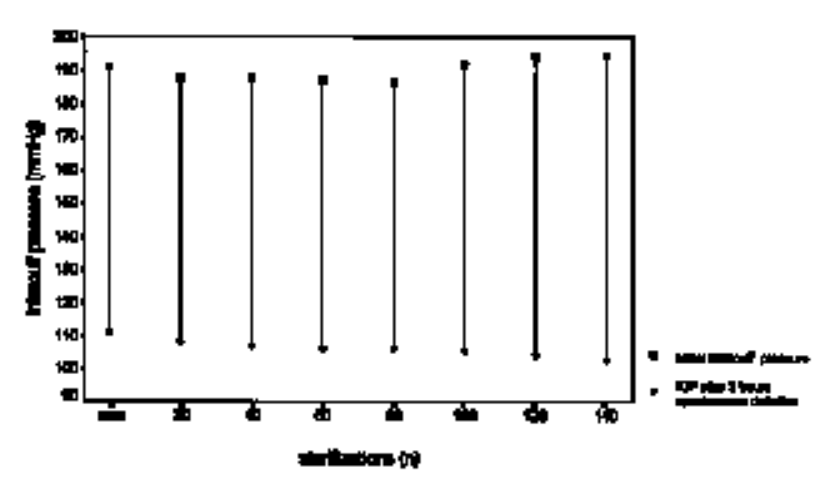

FIGURE 1 M ean initial and final intracuff pressure values throughout the eight tests. 


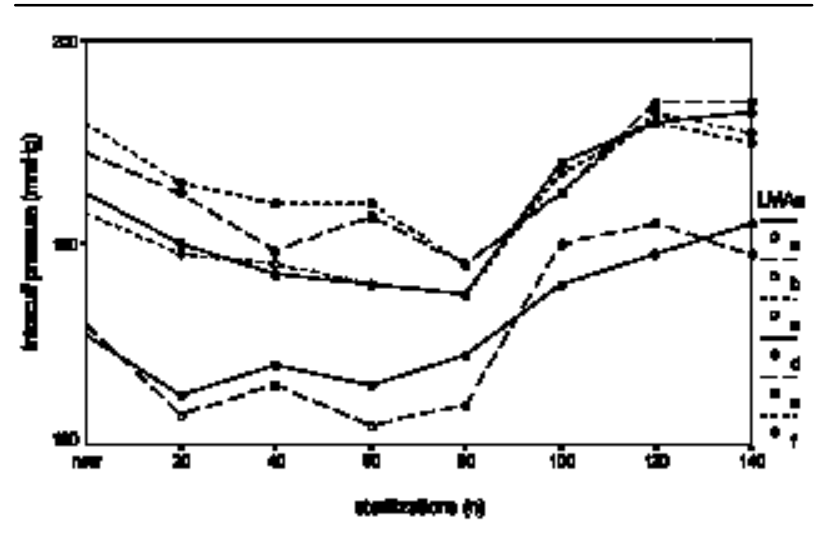

FIGURE 2 Initial intracuff pressure values for each LMA in the eight tests.

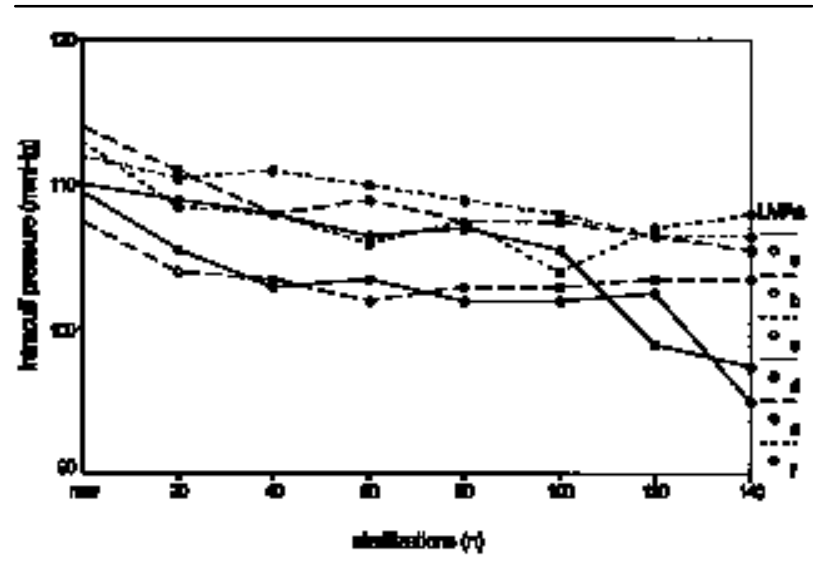

FIGURE 3 Final intracuff pressure values for each LMA in the eight tests.

H owever, two of the LM As showed a greater decrease in the final ICP from 100 sterilizations (LMA " $d$ ") and from 120 sterilizations onwards (LM A " $a$ ").

The thickness of the wall of the cuff of the six LM As was of $694 \pm 17.4 \mu$ (range $673-708$ ). The thickness of the LM As " $a$ " and " $b$ " was less than the others (673 $\mu$ each). These two LMAs proved to be more elastic from the first test (higher compliance, lower initial ICP) and they maintained the same performance until the end of the study (Figure 2). Similarly the decrease in ICP after three hours spontaneous deflation was higher for these two LM As (Figure 3), which was interpreted as being due to higher permeability.
Discussion

After 80-100 sterilizations there is an increase in the initial ICP values that we attribute to a decrease in the elastic properties of the wall of the cuff. This occurrence was observed in all six LM As (Figure 2). In two, the spontaneous deflation produced was more evident than in the others, from 120 sterilizations onwards, which we could relate to an increase in permeability. H owever all the LM As passed the preoperative checklists until the end of the study. In in vivo studies comparing the clinical consequences of the wear of LM As, no increase was observed in the incidence of postoperative complications (sore throat) with the use of the LMAs on up to 40 occasions. $^{8}$ Although we do not know the clinical repercussions of increased permeability of the cuff produced by extensive use, we can affirm that for the set of LM As used in this study, the safe life span could be considered as at least 80-100 uses. This coincides with the usual life span in clinical practice stated by other authors. ${ }^{9}$

Variations in the thickness of the cuff wall justify the differences in ICP values and, consequently, in the elasticity and permeability of the cuff. The manufacturers establish a thickness of $710 \pm 100 \mu$ for a size \#4 LM A. The less thick the membrane, the higher is its permeability. ${ }^{10}$ This explains the differences in the $I C P$ values among the different LM As and why other authors also obtained different ICP values in vitro in studies in which the same methodology was used (mean ICP of 94 and of $107 \mathrm{mmH} g$ after inflation with $30 \mathrm{ml}$ air). ${ }^{6,11}$ Therefore, the thickness of the wall may alter the longevity of LM As. On the other hand, the variation of temperature at which the LMAs are sterilized in different institutions (within the recommended limits), could also explain differences in the durability of the device (M elvyn Dickinson, LM ACO, personal communication). If the sterilization process is carried out at higher temperatures or for a longer time than were used in this study the physical properties of the LM As may be altered prematurely.

Silicone is a material with excellent properties among which we can highlight: long-lasting, heat resistance up to $180^{\circ} \mathrm{C}$, very good elastic properties (along the whole application temperature range), excellent aging resistance, non-toxicity and freedom from smell and taste. However, despite its high resistance, silicone is not everlasting; repeated sterilization at high temperatures produces degradation by a number of different mechanisms. In general, as for any polymer material, its degradation is associated with a reduction of molecular weight and strength. In silicone this is caused by rupturing bonds within the chains by heat, via oxidative degradation or by depoly- 
merization with a loss, in general, of cyclical silanes. Although heat is the main factor that causes this degradation, the repetition of extension-contraction cycles can also produce a loss in elasticity properties of the elastomers. That is why, in the present study, the changes in volume-pressure that are brought about by the habitual use of LM As and especially the passing of the fourth D evice Performance Test (overinflation of the cuff by $50 \%$ ) were simulated. ${ }^{12}$

If it were considered that the longevity of the LMA was exclusively dependent upon the physical properties of the cuff, the manufacturers could extend their guarantee up to 80 uses. Above this figure the cuff starts to lose elasticity. With more than 120 uses some LM As show alterations in their permeability. Variability in the performance observed in each LMA means that the determination of the correct moment to discard a device needs to be dependant on the passing of the preuse checklist rather than on the number of uses. ${ }^{3,8}$

Strict adherence to the manufacturer's recommendations with regard to the correct cleaning and sterilization of the LM As is fundamental to optimise its life span. It should be remembered that the critical point in the cleaning process is to make sure that the cuff is entirely deflated before autoclaving to prevent rupture, particularly of the pilot balloon, as a result of expansion of residual air. Another factor that was not detected in this study but that is known to diminish the longevity of the LMAs is the failure of the valve (the most vulnerable part of the device).

The increase in the "safe" life span of the LMAs observed in the present study should undoubtedly have a favourable effect on the cost-effectiveness analyses carried out previously. ${ }^{13}$

In conclusion, from 80 simulations onwards modifications in the elasticity and permeability of the LMA were observed, depending on the thickness of its wall. $\mathrm{H}$ owever the possibility that alterations occur in other parts of the device or that these are a result of its use in vi vo confirm the statement that the final duration of each LMA will depend on the passing of the pre-use checks recommended by the manufacturer.

Acknowledgement

I would like to thank Dr. Francisco Pulido for the measuring of the thickness of the cuffs.

\section{References}

1 Pennant JH, White PF. The laryngeal mask airway. Its uses in anesthesiology. Anesthesiology 1993; 79: 144-63.

2 M cEwan A I, Mason DG The laryngeal mask airway. J Clin Anesth 1992; 4: 252-7.
3 Brain A IJ. Autoclaving laryngeal masks (Letter). Anesth Analg 1994; 79: 199.

4 Biro P. Damage to laryngeal masks during sterilization (Letter). Anesth Analg 1993; 77: 1079.

5 Figueredo $E$, Vivar-Diago $M$, M uñoz Blanco $F$. L aryngopharyngeal complaints after use of the laryngeal mask airway. Can J Anesth 1999; 46: 220-5.

6 Brimacombe J, Berry A. Laryngeal mask airway cuff pressure and position during anaesthesia lasting one to two hours. Can J Anaesth 1994; 41: 589-93.

7 Brimacombe J, Brain A IJ, Berry A. The laryngeal mask airway instruction manual. H enley-on-Thames, UK: Intavent Research Limited, 1996.

8 Figueredo E, Vivar M, R equena F, Sánchez G, M uñoz F. Repeated use of the laryngeal mask airway and its effect on intra-cuff pressure. $\mathrm{Br}$ J Anaesth 1999; 82: A101.

9 Wat LI, Brimacombe J R, GeeS. L aryngeal mask airway longevity and pilot-balloon failure (Letter). J Clin Anesth 1997; 9: 432.

10 Bernhard WN, Y ost LC, Turndorf H, Cottrell JE, Paegle $R D$. Physical characteristics of and rates of nitrous oxide diffusion into tracheal tube cuffs. Anesthesiology 1978; 48: 413-7.

11 Brimacombe J, Berry A. Laryngeal mask airway cuff pressure and position: the effect of adding nitrous oxide to the cuff (Letter). Anesthesiology 1994; 80: 957-8.

12 Brimacombe JR. Laryngeal mask residual volume and damage during sterilization (L etter). Anesth Analg 1994; 79: 391.

13 Macario A, Chang PC, Stempel D B, Brock-U tne JG A cost analysis of the laryngeal mask airway for elective surgery in adult outpatients. Anesthesiology 1995; 83: 250-7. 